\title{
Unusual outcome of in utero infection and subsequent postnatal super-infection with different PCV2b strains
}

\author{
Dipongkor Saha ${ }^{1,6}$, Uladzimir U. Karniychuk ${ }^{1,8}$, Liping Huang ${ }^{1,7}$, Marc Geldhof ${ }^{1}$, Merijn Vanhee ${ }^{1,3}$, \\ David J. Lefebvre ${ }^{1,4}$, Peter Meerts ${ }^{1,5}$, Richard Ducatelle ${ }^{2}$, Jan V. Doorsselaere ${ }^{3}$, Hans J. Nauwynck ${ }^{1 凶}$
}

1. Laboratory of Virology, Department of Virology, Parasitology and Immunology, Faculty of Veterinary Medicine, Ghent University, Belgium;

2. Department of Pathology, Bacteriology and Poultry Diseases, Faculty of Veterinary Medicine, Ghent University, Belgium;

3. Department of Health Care and Biotechnology, KATHO Catholic University College of South-West Flanders, Belgium;

4. CODA-CERVA, Groeselenberg 99, 1180 Ukkel, Belgium;

5. Ablynx nv, Technologiepark 21, 9052 Zwijnaarde, Belgium;

6. Brain Tumor Research Center, Department of Molecular Neurosurgery, Harvard Medical School and Massachusetts General Hospital, 185 Cambridge Street, Boston, MA-02114, USA;

7. Division of Swine Infectious Diseases, Harbin Veterinary Research Institute, The Chinese Academy of Agricultural Sciences, Harbin, China;

8. Division of Experimental Therapeutics, Toronto General Hospital Research Institute, University Health Network, Toronto, Canada.

VC2002, isolated from postweaning multisystemic wasting syndrome (PMWS)-affected pig, is a mixture of two porcine circovirus genotype $2 b$ (PCV2b) viruses, K2 and K39. Preliminary experiments disclosed short-term adverse effects of K39, but not K2, on porcine foetuses. These findings led to the hypothesis that infection of immuno-incompetent foetuses with K2 confers a status of immunotolerance, and postnatal super-infection with K39 triggers PMWS. To explore this hypothesis, nine 55-day-old foetuses were inoculated in utero (three with $\mathrm{K} 2-10^{4.3} \mathrm{TCID}_{50}$, three with $\mathrm{K} 39-10^{4.3} \mathrm{TCID}_{50}$ and three with medium), and foeto-pathogenicity examined. At 21 days post-inoculation (dpi), K2 did not induce pathology, whereas pathological effects of K39 were evident. Twenty-four 45-day-old foetuses were subsequently inoculated to examine the long-term effect of K2, including six with K2high dose- $10^{4.3} \mathrm{TCID}_{50}$, six with K2-low dose-10 ${ }^{2.3} \mathrm{TCID}_{50}$ and 12 mock-inoculated controls. Both doses resulted in five mummified foetuses and one live-born piglet each (69dpi). K2 was recovered from all mummies. K2 and K2-specific antibodies were not detected in serum of the two live-born piglets at birth, indicating full control of K2 infection. The K2-low dose-infected piglet was immunostimulated at day 2, but not the K2-high dose-infected piglet. Both non-stimulated and stimulated K2-infected piglets were super-inoculated with K39 at day 6 or 8 (taken as 0 days post super-inoculation). Low viral replication was observed in the non-stimulated K2-K39 piglet (up to $10^{3.3} \mathrm{TCID}_{50} / \mathrm{g}$; identified as $\mathrm{K} 39$ ). In contrast, viral replication was extremely high in the stimulated $\mathrm{K} 2-\mathrm{K} 39$ piglet (up to $10^{5.6} \mathrm{TCID}_{50} / \mathrm{g}$ ) and identified as K2, indicating that K2 infection is controlled during foetal life, but emerges after birth upon immunostimulation. However, none of the piglets showed any signs of PMWS.

KEYWORDS PCV2; immunotolerance; PMWS; porcine foetuses

Received: 7 January 2014, Accepted: 5 June 2014,

Published online: 17 June 2014

$\triangle$ Correspondence: Phone: +32-92647373, Fax: +32-92647495,

Email: Hans.Nauwynck@ugent.be 


\section{INTRODUCTION}

Porcine circovirus 2 (PCV2) is the causative agent of postweaning multisystemic wasting syndrome (PMWS), a multifactorial disease that causes severe growth retardation, wasting and increased mortality in weaned pigs (Segalés J, 2012). PCV2 has additionally been isolated from aborted, mummified foetuses and nonviable neonatal piglets (Meehan B M, 2001; Brunborg I M, 2007). PCV2 strains are divided into two major genotypes, PCV2a and PCV2b (Segalés J, 2012), with significant antigenic homology between different strains (McNeilly F, 2001).

Several studies have attempted to experimentally reproduce PMWS by inoculating pigs with PCV2, which mainly led to subclinical infections (reviewed by Segalés J, 2012). At present, scientists working in basic and applied research fields, as well as vaccine development, have problems in studying the pathogenesis of PMWS and designing appropriate vaccine strategies due to the absence of a highly reproducible PMWS model.

Recent studies demonstrated that in utero PCV2 infection during insemination (Sarli G, 2012) or late gestation (Ha Y, 2008) results in live-born infected piglets highly susceptible to disease upon co-infection with other pathogens or immunostimulation (Ha Y, 2008). Two different PCV2 sequences had been identified in one pig (Lefebvre D J, 2008; Gerber P F, 2013). The PCV2 strain, VC2002, was originally isolated from an inguinal lymph node of a Belgian PMWS-affected pig (Meerts P, 2004). Our group subsequently discovered that VC2002 was a mixture of two PCV2b viruses, K2 and K39, displaying 94\% identity at the nucleotide and amino acid levels (Lefebvre D J, 2008). Preliminary analysis of K2 and K39 in porcine foetuses inoculated at 55 days of gestation revealed different biological characteristics (Saha D and Nauwynck HJ, unpublished results). Notably, K39 induced pathol- ogy in foetuses collected at 21 days post-inoculation (76 days of gestation), whereas no pathology was evident in K2-infected foetuses. This finding prompted the hypothesis that in vivo infection of embryos/foetuses with the comparatively less foetopathogenic PCV2, K2, at early stages of gestation (before the development of immunocompetence) confers a status of immunotolerance at birth. Postnatal super-infection of such immunotolerant animals with the highly foetopathogenic PCV2, K39, should therefore cause disease and no recognition by the immune system.

The aim of the present study was to examine the above theory by generating PCV2-immunotolerant pigs via intra-uterine inoculation of $\mathrm{K} 2$ into immuno-incompetent porcine foetuses and analysing the outcome of postnatal super-infection with K39 after birth.

\section{MATERIALS AND METHODS}

\section{Viruses and cells}

Two different PK-15-adapted PCV2b strains, K2 (EF990645) and K39 (EF990646) (Lefebvre D J, 2008), were used. PCV-negative PK-15 cells were grown in minimal essential medium (MEM) containing Earle's salts and GlutaMAX ${ }^{\mathrm{TM}}-\mathrm{I}\left(\mathrm{MEM}+\right.$ GlutaMAX $^{\mathrm{TM}}-\mathrm{I}$, Gibco, Grand Island, USA) and supplemented with $5 \%$ foetal calf serum (FCS), $100 \mathrm{U} / \mathrm{mL}$ penicillin, 0.1 $\mathrm{mg} / \mathrm{mL}$ streptomycin and $0.1 \mathrm{mg} / \mathrm{mL}$ kanamycin. Cell cultures were maintained at $37^{\circ} \mathrm{C}$ in the presence of $5 \% \mathrm{CO}_{2}($ Saha $\mathrm{D}, 2010)$.

\section{Short-term outcome (21 days post inoculation/76 days of gestation)}

At 55 days of gestation, three conventional PCV2seropositive Landrace sows (S1, S2 and S3) were subjected to laparotomy as described earlier by Saha D (2010) (Table 1). Three foetuses of each sow were inoculated: one with $\mathrm{K} 2-10^{4.3} \mathrm{TCID}_{50}$, one with $\mathrm{K} 39$ -

Table 1. Virus replication in different foetal organs after intra-foetal inoculation with K2 or K39 at 55 days of gestation, collected at 21 days post-inoculation

\begin{tabular}{|c|c|c|c|c|c|c|c|c|c|c|c|c|c|c|c|c|c|c|c|c|}
\hline \multirow{3}{*}{$\begin{array}{l}\text { Sow } \\
\text { no. }\end{array}$} & \multirow{3}{*}{$\begin{array}{l}\text { Foetus } \\
\text { no.* }\end{array}$} & \multirow{3}{*}{$\begin{array}{l}\text { PCV2 } \\
\text { strain }\end{array}$} & \multicolumn{18}{|c|}{ PCV2 replication } \\
\hline & & & \multicolumn{2}{|c|}{ Heart } & \multicolumn{2}{|c|}{ Lungs } & \multicolumn{2}{|c|}{ Spleen } & \multicolumn{2}{|c|}{ Liver } & \multicolumn{2}{|c|}{ Kidneys } & \multicolumn{2}{|c|}{ Thymus } & \multicolumn{2}{|c|}{ Tonsils } & \multicolumn{2}{|c|}{ Ileum } & \multicolumn{2}{|c|}{ Cerebrum } \\
\hline & & & VT & IIF & VT & IIF & $\mathrm{VT}$ & IIF & VT & IIF & $\mathrm{VT}$ & IIF & VT & IIF & VT & IIF & VT & IIF & $\mathrm{VT}$ & IIF \\
\hline S1 & L1 & $\mathrm{K} 2$ & 6.3 & 900 & 3.0 & 253 & 5.7 & NA & 5.2 & 10353 & 2.7 & 587 & 5.6 & NA & 3.7 & NA & 4.1 & NA & 2.0 & 10 \\
\hline S2 & R3 & $\mathrm{K} 2$ & 5.5 & 976 & 4.7 & 2363 & 6.3 & 23803 & 5.3 & 12110 & 5.0 & 2890 & 5.8 & 7073 & 4.8 & 3416 & 4.3 & 3850 & 2.5 & 13 \\
\hline S3 & L2 & $\mathrm{K} 2$ & 4.0 & 580 & 3.5 & 1260 & 5.6 & 8320 & 5.0 & 2337 & 2.5 & 880 & 4.8 & 10383 & 4.1 & 1297 & 4.8 & 670 & 2.5 & 17 \\
\hline S1 & L2 & K39 & 6.0 & 3550 & 2.5 & 223 & 4.5 & 1160 & 2.8 & 1337 & $<1.7$ & 10 & 3.0 & 11883 & 3.8 & 13 & 1.8 & 63 & $<1.7$ & 20 \\
\hline $\mathrm{S} 2$ & L2 & K39 & 6.0 & 4027 & 2.2 & 3 & 3.5 & 80 & 3.9 & 1297 & 2.1 & 27 & 3.0 & 30 & 2.8 & 37 & 3.0 & 10 & $<1.7$ & 0 \\
\hline S3 & L3 & K39 & 5.8 & 4350 & 3.0 & 20 & 3.8 & 163 & 4.3 & 1137 & 2.7 & 3 & 4.3 & NA & 2.8 & NA & 1.8 & NA & 2.5 & 0 \\
\hline
\end{tabular}


$10^{4.3} \mathrm{TCID}_{50}$ and one with PK-15 cell culture medium. Inoculation and operative procedures were performed according to the above report (Saha D, 2010). Sows were housed separately, and clinical signs monitored as exactly as described in Saha D (2010). At 21 days post inoculation (dpi), sows were humanely euthanized. All foetuses were examined for gross lesions. Foetal tissue samples were obtained for histopathological examination, virus titration and indirect immunofluorescence analyses (Saha D, 2010). Serum and abdominal fluid from all foetuses and pre-serum (before laparotomy) and post-serum (at the time of euthanasia) of sows were collected.

\section{Long-term outcome (69 days post inoculation/114 days of gestation)}

Four conventional PCV2-seropositive Landrace sows were subjected to laparotomy on the left side of the abdomen at 45 days of gestation. Six foetuses of each sow were inoculated (three with $\mathrm{K} 2$ and three mockinoculated with PK-15 cell culture medium). In the first two sows (S4 and S5), six foetuses (three for each sow) were inoculated with a K2-high dose- $10^{4.3} \mathrm{TCID}_{50} /$ foetus, whereas six foetuses (three for each sow) from the other two sows (S6 and S7) were inoculated with a K2low dose- $10^{2.3} \mathrm{TCID}_{50} /$ foetus (Table 2). The procedures of laparotomy and intra-foetal inoculation of virus or medium were identical to those described previously (Saha D, 2010). At 69 days post inoculation (114 days of gestation), a second laparotomy procedure was carried out on the right side of the abdomen, following which all foetuses were collected (Table 2). Proper care was taken during collection of foetuses to avoid any possibility of PCV2 spread from the virus-inoculated to mockinoculated foetuses. Each of the collected newborn piglets was housed individually in separate isolators.

Blood was collected at birth from the umbilical cord of K2-inoculated and mock-inoculated piglets. Serum samples of the sows were obtained prior to the first (preserum) and second laparotomy (post-serum) procedures.

\section{Super-inoculation of in utero K2- or mock- inoculated piglets with PCV2 (K39)}

Live-born K2- and mock-inoculated colostrum-deprived, caesarean-derived $(\mathrm{CD} / \mathrm{CD})$ piglets from $\mathrm{S} 4$ and S5 or S6 and S7 were oronasally super-inoculated with either $\mathrm{K} 39-10^{4.3} \mathrm{TCID}_{50} /$ pig or medium at days 6 and 8 , respectively. Piglets from S6 and S7 were vaccinated against parvovirus (Parvoject, Merial, Belgium) on day 2. Piglets were monitored daily for PMWS-associated symptoms (Segalés J, 2012). Half of the left and right inguinal lymph nodes (ILNs) were biopsied at 14 and 21 days post super-inoculation (dpsi), respectively (Meerts $\mathrm{P}$, 2005) and the remaining ILNs collected at euthanasia (28 dpsi). All pigs were bled at 0, 7, 14, 21 and 28 dpsi.
Table 2. Clinical outcome of pigs inoculated intra-foetally with PCV2-K2 or mock-inoculated at 45 days of gestation and collected at 69 days post-inoculation (at birth)

\begin{tabular}{lclll}
$\begin{array}{l}\text { Sow } \\
\text { no. }\end{array}$ & $\begin{array}{c}\text { Numbering } \\
\text { of pigs at } \\
\text { birth }\end{array}$ & $\begin{array}{c}\text { Intra-foetal } \\
\text { inoculation } \\
\text { with }\end{array}$ & $\begin{array}{c}\text { Dose } \\
\left(\log _{10} \text { TCID }_{50}\right)\end{array}$ & $\begin{array}{c}\text { Clinical } \\
\text { outcome at } \\
\text { birth }(69 \text { dpi) }\end{array}$ \\
\hline S4 & F1 & K2 & 4.3 & live \\
& F2 & K2 & 4.3 & mummified \\
& F3 & K2 & 4.3 & mummified \\
& F4 & mock & - & live \\
& F5 & mock & - & live \\
S5 & F6 & mock & - & live \\
& F1 & K2 & 4.3 & mummified \\
& F2 & K2 & 4.3 & mummified \\
& F3 & K2 & 4.3 & mummified \\
& F4 & mock & - & live \\
& F5 & mock & - & live \\
S6* & F6 & mock & - & live \\
& F1 & K2 & 2.3 & live \\
& F2 & K2 & 2.3 & mummified \\
& F3 & K2 & 2.3 & mummified \\
& F4 & mock & - & live \\
& F5 & mock & - & live \\
& F6 & mock & - & live \\
\hline S7* & F1 & K2 & 2.3 & mummified \\
& F2 & K2 & 2.3 & mummified \\
& F3 & K2 & 2.3 & mummified \\
& F4 & mock & - & live \\
& F5 & mock & - & live \\
& F6 & mock & - & live \\
\hline
\end{tabular}

*live-born pigs from sows S6 and S7 were immunostimulated.

Tissue suspensions $(10 \%$ or $20 \% \mathrm{wt} / \mathrm{vol})$ were prepared from collected organs, and PCV2 titres determined. PCV2-positive cell numbers in different organs were estimated using indirect immunofluorescence staining (IIF) (Saha D, 2010). For IIF, anti-PCV2 monoclonal antibodies (mAbs) F190 (1:500), F217 (1:100) (McNeilly F, 2001) or biotin-conjugated anti-PCV2 polyclonal antibodies (pAbs) (1:50) in PBS and fluorescein isothiocyanate (FITC)-labelled goat-anti-mouse pAbs (Molecular Probes, USA) or FITC-labelled streptavidin (1:200) (Molecular Probes) in PBS were used as primary and secondary antibodies, respectively. The number of PCV2-positive cells per $10 \mathrm{~mm}^{2}$ of tissue was determined (Saha D, 2010).

To differentiate between K2 and K39, double immunofluorescence staining was performed in ILNs (Saha $\mathrm{D}, 2011)$. The mAbs $114 \mathrm{C} 8$ (IgG1; reacts with $\mathrm{K} 2$ and K39) and 16G12 (IgG2a; reacts with K39) diluted 1:10 (Saha D, 2012a) were used as primary and 1:200 diluted mAbs FITC-labelled goat-anti-mouse IgG1 and goatanti-mouse IgG2a Alexa-Flour 594 (Molecular Probes) as secondary antibodies. The number of PCV2-positive 
cells was determined as above. DNA was extracted from heart and lung tissue suspensions of PCV2-inoculated and adjacent foetuses (21 dpi) as well as piglet sera (69 dpi) (Saha D, 2010). Amplification and sequencing of the PCV2 capsid gene were performed in keeping with previous reports (Saha D, 2010; Saha D, 2012b).

PCV2-specific Ab titres in serum or abdominal fluids of foetuses were determined with the immuno-peroxidase monolayer assay (IPMA) (Saha D, 2010; Saha D, 2014). Sow antibody titres against PCV2 and PRRSV were assessed with IPMA and against porcine parvovirus (PPV) with the hemagglutination inhibition (HI) test (Saha D, 2010). PCV2-specific IPMA Abs in sera of piglets were collected at birth and $0,7,14,21$ and 28 dpsi. PCV2neutralising Abs against K2 or K39 were determined using the classical or sensitive neutralisation assay (Meerts P, 2005; Saha D, 2012c).

\section{RESULTS}

\section{Short-term outcome}

Evaluation of sows - All three sows remained clinically healthy during the study period. The PCV2-specific IPMA Ab titre was 40,960 in both pre- and post-sera of the sows. PRRSV-specific IPMA and PPV-specific HI Ab titres were $<10$ and ranged from $<8$ to 8 , respectively, in pre-serum, and identical in post-serum.

Macroscopic lesions - At 21 dpi, K2-inoculated foetuses had a normal external appearance (Figure 1A). No gross lesions were observed in the different organs, except for enlarged spleen in one foetus (S2R3). K39inoculated foetuses showed oedema, hydrothorax, hydroperitonium, ascites and distended abdomens (Figure 1B).

Microscopic lesions - No histopathological lesions were observed in the different organs of K2-inoculated foetuses, except one, which displayed infiltration of neutrophils in spleen (S2R3). Histopathological lesions, mainly haemorrhage and infiltration of inflammatory cells, were present in heart, lung, liver, spleen and kidney of K39-inoculated fetuses.

PCV2 replication - In K2- and K39-inoculated foetuses, highest PCV2 titres $\left(\log _{10} \mathrm{TCID}_{50} / \mathrm{g}\right)$ were found in the heart $(5.3 \pm 1.2$ and $5.9 \pm 0.1$, respectively). Virus titres in different organs are shown in Table 1.

Moderate to high numbers of PCV2-infected cells/10 $\mathrm{mm}^{2}$ tissue $(900,976$ and 580 in K2- and 4027, 4350 and 3550 in K39-inoculated foetuses) were estimated in the heart. PCV2-positive cell numbers in different organs are presented in Table 1.

Serology - Both K2- and K39-inoculated foetuses were negative $(<10)$ for PCV2-specific IPMA Ab, except one (inoculated with K39), which developed very low anti-PCV2 titres (40).

\section{Long-term outcome}

Evaluation of sows - All four sows remained clinically healthy during the study period. The PCV2-specific IPMA antibody titre was 40,960 in both pre- and post-sera of the sows. PRRSV-specific IPMA and PPV-specific $\mathrm{HI}$ antibody titres were $<10$ and $\leqslant 8$, respectively, in pre-serum, and identical in post-serum.

Evaluation of piglets at birth - Intra-foetal inoculation of six foetuses each from two sows with K2-high dose- $10^{4.3} \mathrm{TCID}_{50}$ at 45 days of gestation resulted in five mummies and one live-born piglet in both cases. Similar results were obtained with six foetuses each from the other two sows inoculated with K2-low dose- $10^{2.3} \mathrm{TCID}_{50}$ (Table 2). Recovered mummies had variable crown-rump lengths, indicating that foetuses died at different times in utero (data not shown). Live-born in utero K2- and
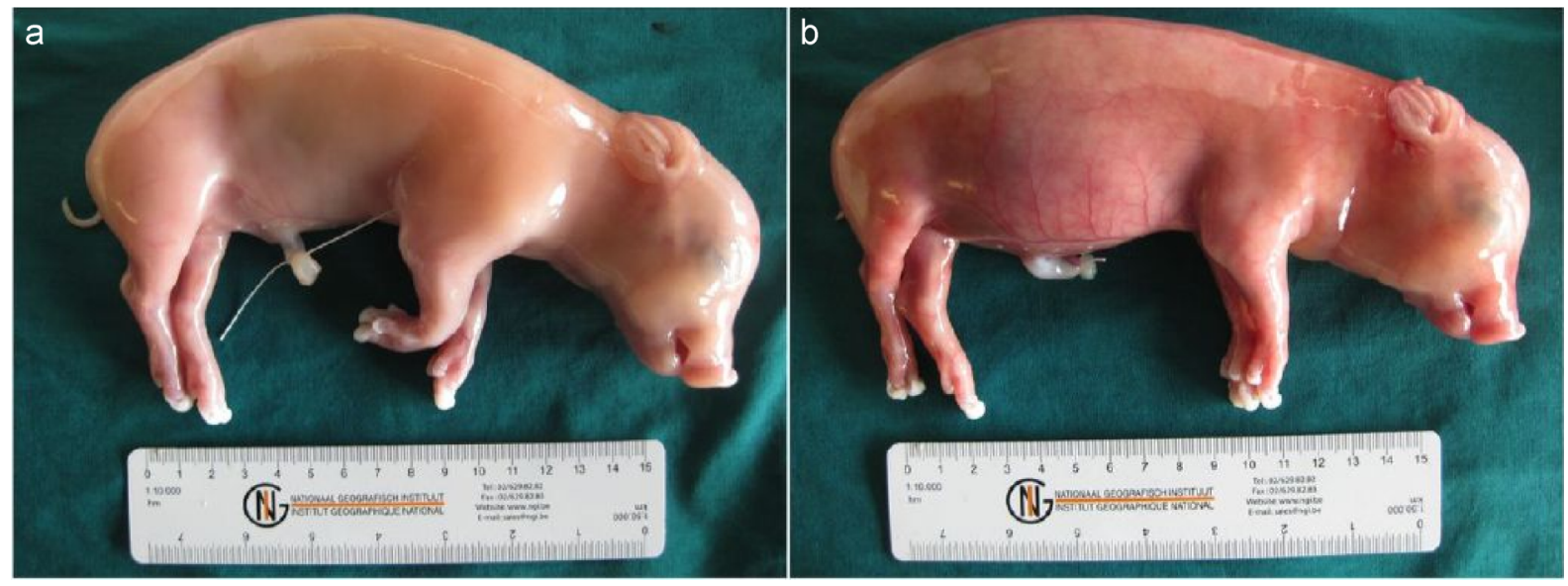

Fig.1. Effects of PCV2 replication on 55-day-old fetuses inoculated collected at 21 days post-inoculation. a) K2inoculated foetus with normal external appearance. b) Subcutaneous oedema and abdominal distension in K39inoculated foetus. 
mock-inoculated piglets appeared clinically normal at birth.

Virus titration in mummies - PCV2 virus was recovered from all mummies with variable titres of $10^{3.7-5.7}$ $\mathrm{TCID}_{50} / \mathrm{g}$ tissue.

PCV2-PCR of serum samples collected at birth - Liveborn piglets, including two K2-inoculated piglets, were negative for PCV2 DNA.

Serology - Live-born K2- and mock-inoculated piglets were negative $(<10)$ for PCV2-specific IPMA Abs at birth (Table 3).

\section{Super-inoculation of in utero K2- or mock- inoculated piglets with PCV2 (K39)}

Evaluation of piglets - All piglets (two K2-K39, six mock-K39 and six mock-mock inoculated) were clinically healthy during the study period. No disease was observed.

PCV2 replication (high-dose K2 in utero) - PCV2 titres in ILNs ( 21 and $28 \mathrm{dpsi}$ ) varied from 2.3 to 3.3 in mock-K39 piglets (S4F4-S4F6). Low-level PCV2 replication (up to 2.3) in ILNs of S4F1 (K2-K39) was observed. PCV2-positive cells were detected only in ILNs of S4F1 (14 dpsi) (Table 3), and identified as $\mathrm{K}^{-} 9^{+} \mathrm{K}^{-}$

PCV2 replication (low-dose K2 in utero) - PCV2 titres in ILNs (S6F4-S6F6) at 21 and 28 dpsi varied from 2.0 to 3.0. One of the piglets ( $\mathrm{S} 6 \mathrm{~F} 1)$ produced very high viral titres in ILNs at 14 dpsi (5.6) and 21 dpsi (5.1), which were significantly reduced at $28 \mathrm{dpsi}$ (1.9) (Table $3)$. Among the mock-K39-inoculated piglets, only S6F4 had two PCV2-positive cells in ILN (21 dpsi). In S6F1 (K2-K39), moderate to high numbers of PCV2-positive cells $/ 10 \mathrm{~mm}^{2}$ were detected in ILNs ( 8 to 86 positive cells/10 $\mathrm{mm}^{2}$ ) (Table 3) and double immunofluorescence staining further confirmed the cells as $\mathrm{K} 2{ }^{+} \mathrm{K} 39^{-}$.

Serology - Super-inoculation of piglets with K39 during postnatal life resulted in seroconversion against PCV2 at 21 dpsi, except in S6F1 and S6F5, which seroconverted at $0 \mathrm{dpsi}$ and $14 \mathrm{dpsi}$, respectively. Highest titres of IPMA Abs were detected at 28 dpsi in all PCV2inoculated piglets. In S4F1 (K2-K39), Ab titres were higher against K39 than K2. Different results were obtained with the other K2-K39 piglet (S6F1), which had already developed PCV2-specific Abs at 0 dpsi. In this case, at 21 and $28 \mathrm{dpsi}$, anti-K2 titres were higher than anti-K39 titres (Table 3). None of the piglets developed neutralising Abs against K2 or K39, except S6F1 (K2K39), which developed neutralising Abs against K2 at 28 dpsi (data not shown).

\section{DISCUSSION}

At 21 dpi, K39 induced pathological lesions, validating earlier descriptions of PCV2 infection in porcine foetuses which caused pathology in internal organs suggestive of heart failure (Saha D, 2010). K2 did not induce pathology in mid-gestational foetuses despite higher titres than K39. One possibility to explain this finding is that $\mathrm{K} 2$ requires more time ( $>3$ weeks) to induce pathology in foetuses. Despite similar PCV2 titres in hearts of K2-

Table 3. PCV2 replication and IPMA antibody titres in pigs inoculated with PCV2-K2 (or mock-inoculated) during prenatal life (at 45 days of gestation) followed by oronasal inoculation with PCV2-K39 (or mock-inoculation) during postnatal life

\begin{tabular}{|c|c|c|c|c|c|c|c|c|c|c|c|c|c|c|c|c|c|c|c|c|c|}
\hline \multirow{4}{*}{$\begin{array}{l}\text { Pig } \\
\text { no. }\end{array}$} & \multicolumn{2}{|c|}{ Prenatal life } & \multicolumn{19}{|c|}{ Prenatal life } \\
\hline & \multirow{3}{*}{$\begin{array}{l}\text { Intra-uterine } \\
\text { inoculation } \\
\text { At } 45 \text { days } \\
\text { of gestation }\end{array}$} & \multirow{3}{*}{$\begin{array}{l}\text { Inoculated } \\
\text { dose of } \\
\text { K2 }\end{array}$} & \multirow{3}{*}{$\begin{array}{l}\text { Oronasal } \\
\text { inoculation } \\
\text { at } 6 \text { or } \\
8 \text { days } \\
\text { after birth }\end{array}$} & \multicolumn{6}{|c|}{ PCV2 replication } & \multicolumn{12}{|c|}{ IPMA antibody titres } \\
\hline & & & & \multicolumn{2}{|c|}{$\frac{14 \mathrm{dpsi}}{\text { ILN }}$} & \multicolumn{2}{|c|}{$\frac{21 \mathrm{dpsi}}{\text { ILN }}$} & \multicolumn{2}{|c|}{$\frac{28 \mathrm{dpsi}}{\text { ILN }}$} & \multicolumn{2}{|c|}{ at birth } & \multicolumn{2}{|c|}{$0 \mathrm{dpsi}$} & \multicolumn{2}{|c|}{$7 \mathrm{dpsi}$} & \multicolumn{2}{|c|}{14 dpsi } & \multicolumn{2}{|c|}{$21 \mathrm{dpsi}$} & \multicolumn{2}{|c|}{$28 \mathrm{dpsi}$} \\
\hline & & & & VT & IIF & VT & IIF & VT & IIF & $\mathrm{K} 2$ & K39 & K2 & K39 & $\mathrm{K} 2$ & K39 & $\mathrm{K} 2$ & K39 & K2 & K39 & K2 & K39 \\
\hline S4F1 & $\mathrm{K} 2$ & $10^{4.3}$ & K39 & $<1.7$ & 2 & 2.3 & 0 & 2.3 & 0 & $<10$ & $<10$ & $<10$ & $<10$ & $<10$ & $<10$ & $<10$ & $<10$ & 10 & 160 & 160 & 40 \\
\hline S4F4 & mock & & K39 & $<1.7$ & 0 & $<1.7$ & 0 & 3.3 & 0 & $<10$ & $<10$ & $<10$ & $<10$ & $<10$ & $<10$ & $<10$ & $<10$ & 160 & 640 & 160 & 10240 \\
\hline S4F5 & mock & & K39 & $<1.7$ & 0 & 2.3 & 0 & 2.3 & 0 & $<10$ & $<10$ & $<10$ & $<10$ & $<10$ & $<10$ & $<10$ & $<10$ & 640 & 2560 & 640 & 10240 \\
\hline S4F6 & mock & & K39 & $<1.7$ & 0 & 2.3 & 0 & 2.3 & 0 & $<10$ & $<10$ & $<10$ & $<10$ & $<10$ & $<10$ & $<10$ & $<10$ & 160 & 2560 & 640 & 10240 \\
\hline S5F4 & mock & & mock & $<1.7$ & 0 & $<1.7$ & 0 & $<1.7$ & 0 & $<10$ & $<10$ & $<10$ & $<10$ & $<10$ & $<10$ & $<10$ & $<10$ & $<10$ & $<10$ & $<10$ & $<10$ \\
\hline S5F5 & mock & & mock & $<1.7$ & 0 & $<1.7$ & 0 & $<1.7$ & 0 & $<10$ & $<10$ & $<10$ & $<10$ & $<10$ & $<10$ & $<10$ & $<10$ & $<10$ & $<10$ & $<10$ & $<10$ \\
\hline S5F6 & mock & & mock & $<1.7$ & 0 & $<1.7$ & 0 & $<1.7$ & 0 & $<10$ & $<10$ & $<10$ & $<10$ & $<10$ & $<10$ & $<10$ & $<10$ & $<10$ & $<10$ & $<10$ & $<10$ \\
\hline S6F1 & K2 & $10^{2.3}$ & K39 & 5.6 & 76 & 5.1 & 86 & 1.9 & 8 & $<10$ & $<10$ & 640 & 640 & 640 & 640 & 640 & 640 & 10240 & 2560 & 40960 & 10240 \\
\hline S6F4 & mock & & K39 & $<1.7$ & 0 & 3.0 & 2 & 2.3 & 0 & $<10$ & $<10$ & $<10$ & $<10$ & $<10$ & $<10$ & $<10$ & $<10$ & 160 & 2560 & 640 & 10240 \\
\hline S6F5 & mock & & K39 & $<1.7$ & 0 & 2.0 & 0 & $<1.7$ & 0 & $<10$ & $<10$ & $<10$ & $<10$ & $<10$ & $<10$ & 40 & 40 & 640 & 2560 & 2560 & 40960 \\
\hline S6F6 & mock & & K39 & $<1.7$ & 0 & 2.7 & 0 & $<1.7$ & 0 & $<10$ & $<10$ & $<10$ & $<10$ & $<10$ & $<10$ & $<10$ & $<10$ & 160 & 2560 & 2560 & 10240 \\
\hline S7F4 & mock & & mock & $<1.7$ & 0 & $<1.7$ & 0 & $<1.7$ & 0 & $<10$ & $<10$ & $<10$ & $<10$ & $<10$ & $<10$ & $<10$ & $<10$ & $<10$ & $<10$ & $<10$ & $<10$ \\
\hline S7F5 & mock & & mock & $<1.7$ & 0 & $<1.7$ & 0 & $<1.7$ & 0 & $<10$ & $<10$ & $<10$ & $<10$ & $<10$ & $<10$ & $<10$ & $<10$ & $<10$ & $<10$ & $<10$ & $<10$ \\
\hline S7F6 & mock & & mock & $<1.7$ & 0 & $<1.7$ & 0 & $<1.7$ & 0 & $<10$ & $<10$ & $<10$ & $<10$ & $<10$ & $<10$ & $<10$ & $<10$ & $<10$ & $<10$ & $<10$ & $<10$ \\
\hline
\end{tabular}

IPMA = Immunoperoxidase monolayer assay. PCV2-specific antibody titres in pig serum during postnatal life were determined using IPMA; dpsi = days post super-inoculation; ILN = inguinal lymph node; VT = Virus titres $\left(\log _{10} \mathrm{TCID}_{50} / \mathrm{g}\right)$; IIF = Indirect immunofluorescence staining (number of PCV2-positive cells/10 $\mathrm{mm}^{2}$ ); Immunostimulated pigs are shown in bold. 
and K39-inoculated foetuses, K2-positive cells were 4.9 times lower than K39-positive cells. This may be due to the small focal distribution of K2 infection, compared to wide dispersion of K39 infection throughout heart tissue. Although K2-positive cell levels were lower, the number of apoptotic cells in hearts of K2- and K39-inoculated foetuses was similar (data not shown).

While K2 did not induce pathology in mid-gestational foetuses, intra-foetal inoculation of a high or low dose of $\mathrm{K} 2$ at 45 days of gestation resulted in a negative longterm effect (10 mummies out of $12 \mathrm{~K} 2$-inoculated foetuses), confirming the hypothesis that $\mathrm{K} 2$ needs longer time to cause foetal damage. In the two in utero K2-inoculated live-born piglets, $\mathrm{K} 2$ virus and specific antibodies were not detected at birth, indicating that young foetuses had fully controlled $\mathrm{K} 2$ infection, possibly through raising an innate immune response. Most cellular components of innate immunity, including natural killer (NK) cells, are found in porcine foetuses before 45 days of gestation (Sinkora M, 2003) but do not show killing activity until activation by microbial pathogens (Sinkora M, 2009). It is possible that NK cells gain their full functional status upon intra-foetal inoculation of PCV2 at 45 days of gestation, which eventually restricts PCV2 replication in foetuses. Wrong inoculations can be excluded, since we have demonstrated $100 \%$ success in performing transuterine, intra-foetal inoculations in the past (Saha D, 2010; Saha D, 2011). The accuracy of intra-foetal inoculation of $\mathrm{K} 2$ is further confirmed by recovery of viruses from the mummies.

Postnatal super-inoculation of in utero mock-inoculated piglets with K39 resulted in low levels of K39 replication, clearly signifys that K39 has different replication kinetics from foetal to early postnatal life. This finding confirms the results of Sanchez RE (2003). Super-inoculation of in utero K2-inoculated piglet (S4F1) with K39 did not result in disease, consistent with the observed low level of viral replication. High PCV2 replication is a prerequisite for the successful development of disease or PMWS (Meerts P, 2006). The late onset of humoral immune response in S4F1 indicates somewhat disturbed immunological response. Serological analysis indicated that viral replication in S4F1 was associated with K39, not K2, in view of the higher anti-K39 Ab levels. Although viral replication was associated with K39 in both K2-K39 (S4F1) and mock-K39 (S4F4 to S4F6) piglets, the S4F1 piglet had exceptionally low anti-K39 titres, compared to mock-K39 piglets. A low anti-K39 titre in S4F1 may indicate a state of partial immunotolerance, which develops due to intra-foetal K2 inoculation at 45 days of gestation. Immunofluorescence staining similarly showed that viral replication in S4F1 was associated with $\mathrm{K} 39$, not $\mathrm{K} 2$, which was further established by sequencing of the capsid gene (data not shown). Our results clearly indicate that $\mathrm{K} 2$ infection is fully controlled by the young foetus without full priming of the immune response. S6F1, inoculated with a low dose of K2 in utero, developed a PCV2-specific immune response early after birth, indicative of re-activation of $\mathrm{K} 2$. This may be associated with parvovirus vaccination after birth. Super-inoculation of S6F1 with K39 led to extremely high viral replication, which was subsequently remarkably reduced, probably due to the appearance of K2-neutralising antibodies. Serological analysis showed higher levels of anti-K2 IPMA Abs than anti-K39 Abs, signifying that viral replication in $\mathrm{S} 6 \mathrm{~F} 1$ is associated with K2, not K39. K2 replication was further confirmed by immunofluorescence staining and sequencing of the capsid gene (data not shown). Based on the results, we suggest that K2 infection is silent during foetal life but activated after birth upon vaccination. Another possibility is that $\mathrm{K} 39$ replication occurs in S6F1, but at a very low level in the period before sampling of the lymph nodes (14 dpsi).

None of the piglets (except S6F1 at $28 \mathrm{dpsi}$ ) developed neutralising Abs. The appearance of neutralising antibodies against PCV2 could be age-dependent. An earlier study by Meerts and co-workers (2006) showed that young pigs, especially CDCD or specific pathogen free (SPF) piglets, developed no or low-level neutralising antibodies against PCV2. Cytotoxic T lymphocytes (CTL) are thought to play a role in determining the immune responses capable of neutralising PCV2.

In conclusion, our study demonstrated that PCV2 K2 is not pathogenic to porcine foetuses over a short-term period, while K39 displays pathogenicity. However, longterm infection with $\mathrm{K} 2$ resulted in the birth of both mummies and viable piglets. Moreover, super-inoculation of live-born K2-infected piglets with K39 did not result in disease. Further studies are necessary to identify PCV2 strains with very low pathogenicity to inoculate foetuses with the aim of producing PCV2-immunotolerant pigs. Work in this context is ongoing.

\section{ACKNOWLEDGMENTS}

We are grateful to Dr. Allan and Dr. McNeilly for providing F190 and F217 antibodies. We additionally thank Zeger, Bart, F. Backer, Sjouke, Lennert, Dominique, Leslie, Annebel, Kalina, Ilias, Eva, Jun, Liping, Amy, Gert, Hossein, Carine, Lieve, Chantal, Melanie, Nele, Irene, Ine and Ytse for help during surgeries and laboratory analyses of the samples. Dipongkor Saha was supported by a BOF scholarship from Ghent University.

\section{COMPLIANCE WITH ETHICS GUIDELINES}

All authors declare no competing interests. The animal 
experiments described in this manuscript were authorised and supervised by the Ethical and Animal Welfare Committee of the Faculty of Veterinary Medicine of Ghent University, Belgium.

\section{AUTHOR CONTRIBUTIONS}

DS and HJN designed the study. DS, HJN, UUK, MG and MV performed the experiments. DS, HJN, DJL and PM analysed data and wrote the manuscript. RD analysed histopathological data. JVD and LH carried out PCR and sequencing.

\section{REFERENCES}

Brunborg I M, Jonassen C M, Moldal T, Bratberg B, Lium B, Koenen F, Schönheit J. 2007. Association of myocarditis with high viral load of porcine circovirus type 2 in several tissues in cases of fetal death and high mortality in piglets. A case study. $\mathrm{J}$ Vet Diagn Invest, 19:368-375.

Gerber P F, Johnson J, Shen H, Striegel D, Xiao C T, Halbur P G, Opriessnig T. 2013. Association of concurrent porcine circovirus (PCV) $2 \mathrm{a}$ and $2 \mathrm{~b}$ infection with PCV associated disease in vaccinated pigs. Res Vet Sci, 95:775-781.

Ha Y, Lee Y H, Ahn K K, Kim B, Chae C. 2008. Reproduction of postweaning multisystemic wasting syndrome in pigs by prenatal porcine circovirus 2 infection and postnatal porcine parvovirus infection or immunostimulation. Vet Pathol, 45:842848.

Lefebvre D J, Costers S, Van Doorsselaere J, Misinzo G, Delputte P L, Nauwynck H J. 2008. Antigenic differences among porcine circovirus type 2 strains, as demonstrated by the use of monoclonal antibodies. J Gen Virol, 89:177-187.

McNeilly F, McNair I, Mackie D P, Meehan B M, Kennedy S, Moffett D, Ellis J, Krakowka S, Allan G M. 2001. Production, characterization and applications of monoclonal antibodies to porcine circovirus 2. Arch Virol, 146:909-922.

Meehan B M, McNeilly F, McNair I, Walker I, Ellis J A, Krakowka S, Allan G M. 2001. Isolation and characterization of porcine circovirus 2 from cases of sow abortion and porcine dermatitis and nephropathy syndrome. Arch Virol, 146:835-842.

Meerts P, Nauwynck H, Sanchez R, Mateusen B, Pensaert M. 2004. Prevalence of porcine circovirus 2 (PCV2)-related wasting on Belgian farms with or without a history of postweaning multisystemic wasting syndrome. Vlaams Diergen Tijds, 73:3138.

Meerts P, Van Gucht S, Cox E, Vandebosch A, Nauwynck H J. 2005. Correlation between type of adaptive immune response against porcine circovirus type 2 and level of virus replication.
Viral Immunol, 18:333-341.

Meerts P, Misinzo G, Lefebvre D, Nielsen J, Bøtner A, Kristensen C S, Nauwynck H J. 2006. Correlation between the presence of neutralizing antibodies against porcine circovirus 2 (PCV2) and protection against replication of the virus and development of PCV2-associated disease. BMC Vet Res, 2:6.

Saha D, Lefebvre D J, Van Doorsselaere J, Atanasova K, Barbé F, Geldhof M, Karniychuk U U, Nauwynck H J. 2010. Pathologic and virologic findings in mid-gestational porcine foetuses after experimental inoculation with PCV2a or PCV2b. Vet Microbiol, 145:62-68.

Saha D, Lefebvre D J, Ducatelle R, Doorsselaere J V, Nauwynck H J. 2011. Outcome of experimental porcine circovirus type 1 infections in mid-gestational porcine foetuses. BMC Vet Res, $7: 64$.

Saha D, Huang L, Bussalleu E, Lefebvre D J, Fort M, Doorsselaere J V, Nauwynck H J. 2012a. Antigenic subtyping and epitopes' competition analysis of porcine circovirus type 2 using monoclonal antibodies. Vet Microbiol, 157:13-22.

Saha D, Doorsselaere J V, Nauwynck H J. 2012b. Instability in vitro of a PCV2 infectious clone containing an insertion between ORF1 and ORF2. Virus Genes, 44:258-261.

Saha D, Lefebvre D J, Ooms K, Huang L, Delputte P L, Van Doorsselaere J, Nauwynck H J. 2012c. Single amino acid mutations in the capsid switch the neutralization phenotype of porcine circovirus 2. J Gen Virol, 93:1548-1555.

Saha D, Del Pozo Sacristán R, Van Renne N, Huang L, Decaluwe R, Michiels A, Rodriguez A L, Rodríguez M J, Durán M G, Declerk I, Maes D, Nauwynck H J. 2014. Anti-porcine circovirus type 2 (PCV2) antibody placental barrier leakage from sow to fetus: impact on the diagnosis of intra-uterine PCV2 infection. Virol Sin, 29:136-138.

Sanchez R E, Meerts P, Nauwynck H J, Pensaert M B. 2003. Change of porcine circovirus 2 target cells in pigs during development from foetal to early postnatal life. Vet Microbiol, 95:15-25.

Sarli G, Morandi F, Panarese S, Bacci B, Ferrara D, Bianco C, Fusaro L, Bacci M L, Galeati G, Dottori M, Bonilauri P, Lelli D, Leotti G, Vila T, Joisel F, Allan G, Benazzi C, Ostanello F. 2012. Reproduction in porcine circovirus type 2 (PCV2) seropositive gilts inseminated with PCV2b spiked semen. Acta Vet Scand, $54: 51$.

Segalés J. 2012. Porcine circovirus type 2 (PCV2 infections: clinical signs, pathology and laboratory diagnosis. Virus Res, 164:10-19.

Sinkora M, Sun J, Sinkorova J, Christenson R K, Ford S P, Butler J E. 2003. Antibody repertoire development in fetal and neonatal piglets. VI. B-cell lymphogenesis occurs at multiple sites with differences in the frequency of in-frame rearrangements. J Immunol, 170:1781-1788.

Sinkora M, Butler J E. 2009. The ontogeny of the porcine immune system. Dev Comp Immunol, 33:273-283. 